\title{
Analisis Potensi dan Strategi Pemanfaatan Limbah Kelapa Sawit di Kabupaten Labuhanbatu
}

\section{The Potential Analysis and Strategy of Palm Oil Waste Distribution in Labuhanbatu Regency}

\author{
Sutan Harahap1), Zulkifli Lubis²), Abdul Rahman'3) \\ 1) Program Studi Magister Agribisnis, Pascasarjana, Universitas Medan Area, Indonesia \\ 2) Universitas Sumatera Utara, Indonesia \\ 3) Fakultas Pertanian, Universitas Medan Area, Indonesia
}

\begin{abstract}
Abstrak
Penelitian ini untuk mengetahui berapa besar potensi limbah padat dan cair yang dihasilkan perkebunan kelapa sawit di daerah penelitian, metode pemanfaatan limbah kelapa sawit di daerah penelitian, dan mengetahui prioritas strategi pemanfaatan limbah kelapa sawit di Kabupaten Labuhanbatu. Berdasarkan matriks IFAS diperoleh sumbu $\mathrm{x}=1.02$ dan dari matriks EFAS diperoleh sumbu $\mathrm{y}=0.45$ se-hingga $(\mathrm{x}, \mathrm{y})=(1.02,0.45)$ berada di kuadran I (positif, positif). Matriks kuadran SWOT PT Pangkatan Indonesia dimana posisi tersebut menunjukkan PT Pangkatan Indonesia sebagai perusahaan yang kuat dan berpeluang, rekomendasi strategi yang diberikan adalah berpotensi, artinya perusahaan dalam kondisi prima dan mantap sehingga sangat dimungkinkan untuk terus melakukan poetnsi yang besar, memperbesar pertumbuhan dan meraih kemajuan secara maksimal dalam pengolahan limbah padat dan cair. Selanjutnya digunakan matriks SWOT berdasarkan hasil klasifikasi terhadap berbagai kemungkinan dari faktor internal dan eksternal untuk mempermudah dalam pengambilan keputusan. Berdasarkan matriks IFAS diperoleh sumbu $\mathrm{x}=1.02$ dan dari matriks EFAS diperoleh sumbu $\mathrm{y}=0.45$ se-hingga $(\mathrm{x}, \mathrm{y})=(1.41,0.64)$ berada di kuadran I (positif,positif). Matriks kuadran SWOT PT Sinar Pendawa dimana posisi tersebut menunjukkan PT Sinar Pendawa sebagai perusahaan yang kuat dan berpeluang, rekomendasi strategi yang diberikan adalah berpotensi. Kata Kunci : Potensi dan Strategi Pemanfaatn Limbah Pabrik Kelapa Sawit
\end{abstract}

\begin{abstract}
This study is to find out how much the potential for solid and liquid waste produced by oil palm plantations in the study area, methods of utilizing palm oil waste in the study area, and to determine the priority strategies for the utilization of palm oil waste in Labuhanbatu Regency. Based on the IFAS matrix, the $x$-axis is obtained $=1.02$ and from the EFAS matrix, the $y$-axis is obtained $=0.45$ so that $(x, y)=(1.02,0.45)$ is in quadrant I (positive, positive). PT Pangkat Indonesia's SWOT quadrant matrix where the position shows PT Pangkat Indonesia as a strong and potential company, the strategy recommendations provided are potential, meaning that the company is in prime and stable condition so that it is possible to continue to carry out large potentials, increase growth and make progress in a progressive manner in the treatment of solid and liquid waste. Furthermore, the SWOT matrix is used based on the results of the classification of various possibilities of internal and external factors to facilitate decision making. Based on the IFAS matrix, the $x$-axis is obtained $=1.02$ and the EFAS matrix is obtained by the $y$-axis $=0.45$ so that $(x, y)=(1.41 .0 .64)$ is in quadrant I (positive, positive). PT Sinar Pendawa's SWOT quadrant matrix where the position shows PT Sinar Pendawa as a strong and potential company, the strategy recommendations given are potential.

Keywords: Potential and Strategy of Palm Oil Mill Waste Utilization
\end{abstract}

How to Cite: Harahap, S., Z. Lubis, \& Abdul Rahman. (2019). Analisis Potensi dan Strategi Pemanfaatan Limbah Kelapa Sawit di Kabupaten Labuhanbatu. Jurnal Ilmiah Magister Agribisnis, 1(2) 2019: 162-176,

${ }^{*}$ E-mail: $\underline{\text { Rahman@uma.ac.id }}$

ISSN 2550-1305 (Online) 
Harahap, S., Z. Lubis, \& Abdul Rahman. Analisis Potensi dan Strategi Pemanfaatan Limbah Kelapa Sawit di Kabupaten Labuhanbatu

\section{PENDAHULUAN}

Salah satu subsektor pertanian adalah perkebunan. Ada dua pola dalam pengelolaan usaha perkebunan yang salah satunya adalah pola perkebunan rakyat yang dicirikan oleh berbagai kelemahan antara lain: diusahakan di lahan relatif sempit dengan cara tradisional, produktivitas dan mutu rendah, posisi dalam pemasaran hasil lemah. Sebaliknya pola perkebunan besar dimana pengelolaannya diusahakan secara modern, dengan teknologi maju (Mubyarto, 2001).

Kelapa sawit mempunyai peran yang cukup strategis dalam perekonomian Indonesia. Pertama, minyak sawit merupakan salah satu dari sembilan bahan pokok kebutuhan masyarakat sehingga harganya harus terjangkau oleh seluruh lapisan masyarakat. Kedua, sebagai salah satu komoditas pertanian andalan ekspor non migas, sebagai sumber perolehan devisa maupun pajak. Ketiga, menciptakan kesempatan kerja dan sekaligus meningkatkan kesejahteraan masyarakat (Soetrisno, 2008). Laju pertumbuhan areal perkebunan kelapa sawit ditandai dengan peningkatan kenaikan produksi Crude Palm Oil (CPO). Negara-negara yang dapat mengolah kelapa sawit dengan baik bisa mendapatkan hasil yang sangat menguntungkan dari industri komoditas ini (Parlina, 2013). Luas areal perkebunan kelapa sawit yang ada di Sumatera Utara, apabila dibagi menurut pengusahaannya terdapat perkebunan rakyat seluas 815.071 ha dengan produksi 2.829 .280 ton, perkebunan swasta seluas 425.551 ha dengan produksi 4.934 .556 ton dan lahan perkebunan PTPN seluas 388.534 hektar dengan produksi 4.461.398 ton (Dinas Perkebunan Sumut, 2015).

Dalam proses pengolahan tandan buah segar (TBS) menjadi minyak kelapa sawit akan dihasilkan sisa produksi berupa limbah padat dan cair (Prabowo, 2014). Limbah kelapa sawit adalah sisa hasil tanaman kelapa sawit yang tidak termasuk dalam produk utama atau merupakan hasil ikutan dari pengolahan kelapa sawit. Berdasarkan tempat pembentukan limbah kelapa sawit dapat digolongkan menjadi dua jenis yaitu limbah perkebunan kelapa sawit dan limbah industry kelapa sawit. (Eko, 2013).

Kabupaten Labuhanbatu merupakan salah satu pusat perkebunan kelapa sawit di Sumatera Utara, baik yang dikelola oleh perusahaan negara / swasta maupun perkebunan rakyat. Tahun 2015, perkebunan memberikan sumbangan yang cukup besar terhadap produk domestik regional bruto (PDRB) kabupaten, yaitu mencapai 27,33 persen dan ini mendominasi penggunaan lahan. Komoditi andalan Kabupaten Labuhanbatu adalah kelapa sawit sebagai bahan baku CPO (crude palm oil). Luas

perkebunan di Labuhanbatu 406.718,02 hektar atau 44,10 persen dari luas keseluruhan wilayah Labuhanbatu. Perkebunan kelapa sawit 303.040,13 hektar, baik yang dikelola perkebunan besar maupun swasta rakyat. Di daerah ini terdapat sebesar 77.271 Ha kebun sawit rakyat atau 50,23 persen dari seluruh perkebunan 
kelapa sawit rakyat di Sumatera Utara. Walaupun luas perkebunan rakyat lebih besar, namun hasil produksinya hampir sama dengan perkebunan swasta yang luasnya lebih rendah dari kebun rakyat (Dishutbun Labuhanbatu, 2015).

Tanaman kelapa sawit menghasilkan 3 jenis limbah utama yang dapat digunakan sebagai bahan pakan ternak yaitu pelepah daun kelapa sawit, lumpur minyak sawit dan bungkil inti sawit. Menurut Kurniati (2008) Limbah ini digolongkan dalam tiga jenis yaitu limbah padat, limbah cair dan limbah gas. Menurut Devendra pernyataan Devendra (1990), siklus pemangkasan setiap 14 hari, tiap pemangkasan sekitar 3 pelepah daun dengan berat 1 pelepah mencapai $10 \mathrm{~kg}$. Satu ha lahan ditanami sekitar 148 pohon sehingga setiap 14 hari akan dihasilkan \pm 4.440 kgatau $8.880 \mathrm{~kg} / \mathrm{bulan} / \mathrm{ha}$. Kandungan bahan kering dari pelepah daun sawit sebesar 35\% sehingga jumlah bahan kering pelepah sawit/bulan/ha sebesar $3.108 \mathrm{~kg}$. Kebun sawit yang sudah produktif seluas 1 ha mampu menyediakan pelepah sawit/pakan ternak sebanyak 3 ekor ternak sapi.

Strategi pemanfaatan limbah kelapa sawit pada hakikatnya adalah pelaksanaan pembangunan agribisnis suatu komoditi di suatu wilayah yang disesuaikan dengan kemampuan fisik dan sosial wilayah tersebut, serta tetap menghormati peraturan perundangan yang berlaku. Melihat potensi limbah kelapa sawit yang cukup besar, sudah selayaknya perlu pengkajian strategi pengembangan ke depan dengan mempertimbangkan faktor strategis internal dan eksternal yang mempengaruhinya. Berdasarkan uraian latar belakang di atas maka penting untuk melakukan penelitian tentang strategi pemanfaatan limbah kelapa sawit di Kabupaten Labuhanbatu.

\section{METODE PENELITIAN}

Penelitian ini dilakukan secara purposive sampling yaitu lokasi yang dipilih adalah Kabupaten Labuhanbatu, karena merupakan sentra perkebunan kelapa sawit di Provinsi Sumatera Utara. Penelitian dibatasi pada analisis potensi menggunakan analsisi deskriptif dan analisis strategi pemanfaatan limbah kelapa sawit dengan analisis SWOT (Strengths, Weakness, Opportunities, Treats). Penelitian dilakukan selama tiga bulan mulai Maret hingga Mei 2017.

Dengan menggunakan metode deskriptif untuk menganalisis berapa jumlah tenaga kerja yang digunakan dalam kegiatan pemanfaatan limbah kelapa sawit di daerah penelitian. Kemudian tujuan lainnya dianalisis dengan menggunakan metode deskriptif yaitu dengan dokumentasi dan pengumpulan data sekunder dengan instansi terkait tentang metode pemanfaatan limbah kelapa sawit di daerah penelitian. Dan terakhir dianalisis dengan menggunakan metode deskriptif yaitu dengan analisis SWOT. Analisis strategi pemanfaatan limbah kelapa sawit dilakukan dengan metode analisis SWOT (Strengths Opportunities Weaknesses dan Threat). 
Harahap, S., Z. Lubis, \& Abdul Rahman. Analisis Potensi dan Strategi Pemanfaatan Limbah Kelapa Sawit di Kabupaten Labuhanbatu

Analisis ini didasarkan pada logika yang dapat memaksimalkan kekuatan (Strengths) dan peluang (Opportunities) suatu prospek pemanfaatan dan secara bersamaan dapat pula meminimalkan kelemahan (Weaknesses) dan ancaman (Threat).

\section{HASIL DAN PEMBAHASAN}

\section{Analisis SWOT Rumusan Limbah Padat Pada PT. Pangkatan Indonesia}

Hasil analisis pengelolaan limbah padat dan cair pada PT Pangkatan Indonesia menunjukkan adanya beberapa potensi yang dapat dirumuskan sebagai upaya optimalisasi untuk perbaikan kinerja perusahaan. Rumusan optimalisasi akan disusun menggunakan analisis SWOT yang merupakan salah satu instrumen analisis yang dipandang cukup ampuh. Keampuhan tersebut terletak pada kemampuan para penentu strategi yang berperan dalam organisasi (Siagian 2004). Menurut Retnowati (2011) analisis situasi SWOT merupakan awal proses perumusan strategi untuk menemukan kesesuaian strategis antara peluang eksternal dan kekuatan internal, di samping memperhatikan ancaman eksternal dan kelemahan internal. Kekuatan dan kelemahan internal adalah segala kegiatan dalam kendali organisasi yang bisa dilakukan dengan sangat baik atau buruk. Kekuatan dan kelemahan tersebut ada dalam kegiatan manajemen, pemasaran, keuangan/akuntansi, produksi/operasi, penelitian dan pengembangan, serta sistem informasi manajemen di setiap perusahaan. Peluang dan ancaman eksternal juga dapat diidentifikasi merujuk pada peristiwa dan tren ekonomi, sosial, budaya, demografi, lingkungan, politik, hukum, pemerintahan, teknologi, dan persaingan yang dapat menguntungkan atau merugikan suatu organisasi secara berarti di masa depan. Peluang dan ancaman sebagian besar di luar kendali suatu organisasi (David 2004). Hasil identifikasi faktor internal dan eksternal dapat digunakan untuk merumuskan analisis matriks internal factor analysis summary (IFAS) dan matriks external factor analysis summary (EFAS).Matriks IFAS dan EFAS menunjukkan skor, bobot, dan jumlah nilai total dari masing-masing faktor berdasarkan hasil observasi dan evaluasi kondisi PT.Pangkatan Indonesia seperti tercantum pada tabel 1 berikut ini :

Faktor internal (kekuatan dan kelemahan) dalam pemanfaatan limbah padat

Tabel 1. Matriks Analsis Secara Faktor Internal

\begin{tabular}{llcc}
\hline Kekuatan & Bobot & Skor & Total \\
\hline $\begin{array}{l}\text { Melaksanakan dan mengevaluasi kegiatan } \\
\text { pengelolaan limbah cair dan padat secara }\end{array}$ & 4 & 0,18 & 0,72 \\
$\begin{array}{l}\text { rutin sesuai dengan ketentuan yang berlaku } \\
\text { Berkomitmen dalam peraturan SOP } \\
\text { perushaan dalam pengolahan limbah kelapa }\end{array}$ & & & \\
sawit secara konsisten & 0,17 & 0,51 \\
\hline
\end{tabular}




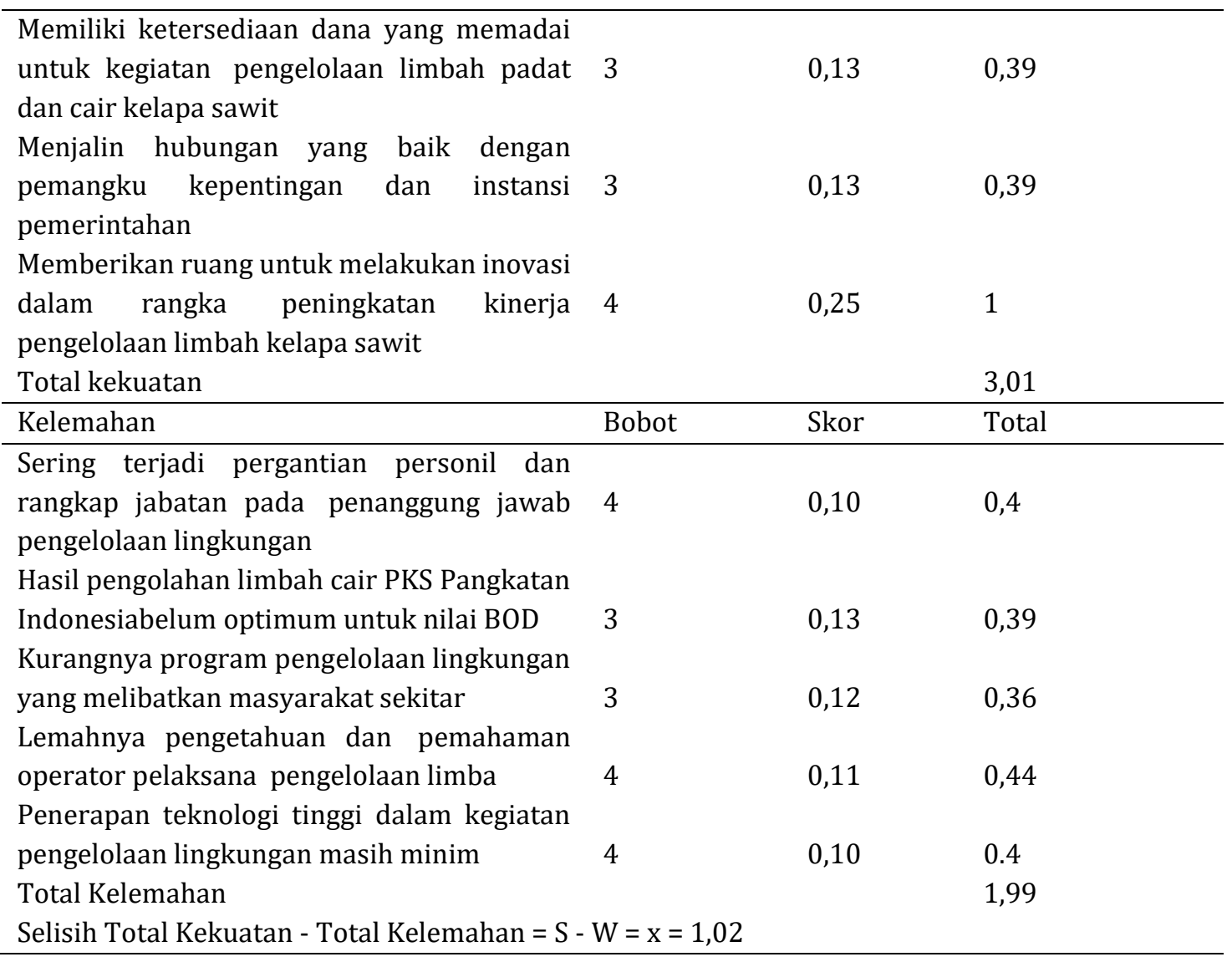

Sumber : Data Primer (diolah), 2019

Faktor eksternal (peluang dan ancaman) dalam pemanfaatan limbah padat Tabel 2. Matriks Analsis Secara Faktor Eksternal

\begin{tabular}{|c|c|c|c|}
\hline Peluang & Bobot & Skor & Total \\
\hline $\begin{array}{l}\text { Potensi kerjasama dengan pihak ketiga dalam } \\
\text { pemanfaatan gas metan dari limbah cair } \\
\text { kelapa sawit }\end{array}$ & 4 & 0,20 & 0,8 \\
\hline $\begin{array}{l}\text { Banyaknya alternatif pengelolaan cangkang } \\
\text { dan fiber bekerjasama dengan pihak ketiga } \\
\text { Belum adanya kegiatan pemanfaatan limbah }\end{array}$ & 3 & 0,20 & 0,6 \\
\hline $\begin{array}{l}\text { padat untuk pemberdayaan masyarakat } \\
\text { Total Peluang }\end{array}$ & 3 & 0,18 & $\begin{array}{l}0,54 \\
1,94\end{array}$ \\
\hline Ancaman & Bobot & Skor & Total \\
\hline $\begin{array}{l}\text { Perubahan peraturan kebijakan dalam } \\
\text { pengolahan limbah kelapa sawit } \\
\text { Terbatasnya jumlah lembaga pengelola }\end{array}$ & 4 & 0,17 & 0,68 \\
\hline $\begin{array}{l}\text { limbah dan laoratorium penguji yang } \\
\text { memenuhi ketentuan disekitar lokasi PKS } \\
\text { Pangkatan Indonesia }\end{array}$ & 3 & 0,15 & 0,45 \\
\hline $\begin{array}{l}\text { Ketentuan pemerintah dan pemangku } \\
\text { kepentingan untuk pemenuhan standar }\end{array}$ & 3 & 0,12 & 0,36 \\
\hline
\end{tabular}


Harahap, S., Z. Lubis, \& Abdul Rahman. Analisis Potensi dan Strategi Pemanfaatan Limbah Kelapa Sawit di Kabupaten Labuhanbatu

limbah sawit berkelanjutan yang terhadap

lingkungan

Total Ancaman

1,49

Selisih Total Peluang - Total Tantangan $=0-\mathrm{T}=\mathrm{y}=0,45$

Berdasarkan matriks IFAS diperoleh sumbu $\mathrm{x}=1.02$ dan dari matriks EFAS diperoleh sumbu $y=0.45$ se-hingga $(x, y)=(1.02,0.45)$ berada di kuadran I (positif,positif).

Matriks kuadran SWOT PT Pangkatan Indonesia dimana posisi tersebut menunjukkan PT Pangkatan Indonesia sebagai perusahaan yang kuat dan berpeluang, rekomendasi strategi yang diberikan adalah berpotensi, artinya perusahaan dalam kondisi prima dan mantap sehingga sangat dimungkinkan untuk terus melakukan poetnsi yang besar, memperbesar pertumbuhan dan meraih kemajuan secara maksimal dalam pengolahan limbah padat dan cair. Selanjutnya digunakan matriks SWOT berdasarkan hasil klasifikasi terhadap berbagai kemungkinan dari faktor internal dan eksternal untuk mempermudah dalam pengambilan keputusan sebagai berikut :

Untuk mengoptimalkan pengelolaan limbah padat, perusahaan dapat melakukan upaya pengurangan limbah padat dan cair dengan menginventarisasi seluruh limbah yang dihasilkan agar dapat dikelola dengan baik. Salah satu upaya yang dapat dioptimalkan adalah melakukan pengomposan dan aplikasi mealui lahan sawit.Matriks SWOT yang telah disusun menghasilkan 4 strategi yang dapat diterapkan sebagai upaya optimalisasi kinerja pengelolaan lingkungan PKS Pangkatan Indonesia yaitu :

Tabel 3. Matrik Analisa SWOT PT. Pangkatan Indonesia

\begin{tabular}{|c|c|c|}
\hline Faktor Internal & Strengths (S) Kekuatan & Weaknesses (W) Kelemahan \\
\hline Faktor Eksternal & \begin{tabular}{lr} 
- & Perusahaan \\
menerapkan & system \\
HACCP & (Hazard \\
Analysis Critical Control \\
Point), di & dalamnya \\
termasuk & upaya \\
pencegahan & dampak \\
teransportasi. & \\
- Perusahaan & terus \\
berupaya & melakukan \\
inisiatif & untuk \\
menghemat & \\
penggunaan & air \\
memiliki ketersediaan \\
dana yang & memadai \\
untuk & \multicolumn{1}{c}{ kegiatan }
\end{tabular} & $\begin{array}{l}\text { - Membakar tankos untuk mendapatkan abu } \\
\text { kalium. Pada saat ini incinerator sudah mulai } \\
\text { ditinggalkan. } \\
\text { - Limbah yang keluar dari PKS PT. Pangkatan } \\
\text { Indonesia sebenarnya belum bisa dikatakan } \\
\text { 100\% limbah, lebih tepat dikatakan produk } \\
\text { sampingan. } \\
\text { - Pengomposan (composting), system ini tidak } \\
\text { disarankan karena memerlukan lokasi dan } \\
\text { biaya yang besar. } \\
\text { - Limbah menjadi perhatian PKS PT. Pangkatan } \\
\text { Indonesia adalah limbah cair dari pabrik. }\end{array}$ \\
\hline
\end{tabular}




\begin{tabular}{|c|c|c|}
\hline & $\begin{array}{l}\text { pengelolaan limbah } \\
\text { pabrik kelapa sawit } \\
\text { - Perusahaan } \\
\text { melaksanakan } \\
\text { pengukuran baku mutu } \\
\text { limbah pabrik kelapa } \\
\text { sawit persemester } \\
\text { - Komitmen untuk } \\
\text { menjadi perusahaan } \\
\text { yang ramah lingkungan } \\
\text { juga diupayakan dengan } \\
\text { menurunkan beban } \\
\text { pencemaran. }\end{array}$ & \\
\hline $\begin{array}{l}\text { Opportunitties }(0) \\
\text { Peluang }\end{array}$ & $\begin{array}{l}\text { Strategi SO } \\
\text { (Strengths } \\
\text { Opportunities) }\end{array}$ & $\begin{array}{l}\text { Strategi WO } \\
\text { Minimalisasi kelemahan dengan memanfaatkan } \\
\text { peluang }\end{array}$ \\
\hline $\begin{array}{lr}\text { - } r \text { Mendapatkan } \\
\text { teknologi } \quad \text { yang } \\
\text { lebih ramah } \\
\text { lingkungan. } \\
\text { - Mendapatkan } \\
\text { nilai } \quad \text { tambah } \\
\text { secara ekonomi } \\
\text { (economic } \\
\text { benefit). } \\
\text { - Abu boiler dapat } \\
\text { diaplikasikan } \\
\text { langsung sebagai } \\
\text { sumber pupuk. } \\
\text { Tankos dan air } \\
\text { limbah untuk } \\
\text { kompos. }\end{array}$ & $\begin{array}{l}\text { - Keterbatasan lahan di } \\
\text { PT. Pangkatan } \\
\text { Indonesia } \\
\text { menggunakan kolam } \\
\text { terbuka. } \\
\text { - Perubahan alat proses } \\
\text { membawa dampak pada } \\
\text { perubahan kualitas, } \\
\text { kuantitas dan jenis } \\
\text { limbah yang dihasilkan } \\
\text { - Terdapat } 2 \text { sumber } \\
\text { pencemaran gas yang } \\
\text { keluar dari PKS PT. } \\
\text { Pangkatan Indonesia } \\
\text { yaitu boiler dan } \\
\text { incinerator. }\end{array}$ & $\begin{array}{l}\text { - Melakukan evaluasi dan perbaikan kinerja } \\
\text { instalasi pengolahan air limbah agar out limbah } \\
\text { sesuai ketentuan. } \\
\text { - Penerapan teknologi pemanfaatan limbah } \\
\text { padat dan cair sebagai kompos, pakan ternak } \\
\text { dengan pihak ketiga untuk disalurkan ke } \\
\text { masyarakat } \\
\text { - Melibatkan masyarakat sekitar dalam } \\
\text { pemanfaatan limbah. } \\
\text { [ }\end{array}$ \\
\hline $\begin{array}{l}\text { Threats }(\mathrm{T}) \\
\text { Ancaman }\end{array}$ & $\begin{array}{l}\text { Strategi ST } \\
\text { (Strengths Threats) }\end{array}$ & $\begin{array}{l}\text { Strategi WT } \\
\text { Minimalisasi kelemahan dengan menyikapi } \\
\text { ancaman }\end{array}$ \\
\hline $\begin{array}{l}\text { - Perubahan } \\
\text { kebijakan dan } \\
\text { peraturan terkait } \\
\text { pengelolaan } \\
\text { lingkungan. } \\
\text { - Terbatasnya } \\
\text { jumlah lembaga } \\
\text { pengelola limbah }\end{array}$ & $\begin{array}{l}\text { - Memberikan masukan } \\
\text { dan } \quad \text { pendekatan } \\
\text { persuasif dalam } \\
\text { penetapan kebijakan } \\
\text { pemerintah agar tidak } \\
\text { memberatkan } \\
\text { perusahaan. }\end{array}$ & $\begin{array}{l}\text { - Melakukan penyesuaian kegiatan pengelolaan } \\
\text { dan pemantauan limbah padat dan cair sesuai } \\
\text { ketentuan yang berlaku. } \\
\text { - Mengadakan pelatihan untuk meningkatkan } \\
\text { kompetensi sumber daya manusia karyawan } \\
\text { yang menangani pengelolaan limbah pabrik } \\
\text { kelapa sawit PT. Pangkatan Indonesia. }\end{array}$ \\
\hline
\end{tabular}


Harahap, S., Z. Lubis, \& Abdul Rahman. Analisis Potensi dan Strategi Pemanfaatan Limbah Kelapa Sawit di Kabupaten Labuhanbatu

\begin{tabular}{|c|c|}
\hline $\begin{array}{l}\text { dan laboratorium } \\
\text { penguji yang } \\
\text { memenuhi } \\
\text { ketentuan yang } \\
\text { berlaku disekitar } \\
\text { PKS PT. Pangkatan } \\
\text { Indonesia. }\end{array}$ & $\begin{array}{lr}- & \text { Mencari } \\
\text { dan } & \text { menentukan } \\
\text { lembaga } & \text { pengelola } \\
\text { limbah } & \text { serta } \\
\text { laboratorium } & \text { penguji } \\
\text { yang } & \text { memiliki } \\
\text { akreditasi dari lembaga } \\
\text { yang berwenang. }\end{array}$ \\
\hline
\end{tabular}

Berdasarkan beberapa strategi yang telah disusun, prioritas strategi yang digunakan adalah strategi SO (strengths opportunities). Penentuan strategi ini berdasarkan pada posisi perusahaan di kuadran 1 hasil dari matriks kuadranSWOT PKS Pangkatan Indonesia. Optimalisasi kinerja pengelolaan limbah padat dapat dilakukan dengan upaya minimisasi melalui inventarisasi seluruh limbah padat yang dihasilkan PKS Pangkatan Indonesia agar dapat dikelola dengan baik. Salah satu programnya adalah mengurangi timbulan limbah B3 berupa oli bekas dan filter bekas dari operasional genset. Hal ini dapat dilakukan dengan memanfaatkan cangkang dan fiber sebagaibahan bakar boiler untuk menjalankan turbin non processing sehingga mampu menggantikan operasional genset.

\section{Analisis SWOT Rumusan Limbah Cair Pada PT. Sinar Pandawa}

Hasil analisis pengelolaan limbah padat dan cair pada PT Sinar Pandawa menunjukkan adanya beberapa potensi yang dapat dirumuskan sebagai upaya optimalisasi untuk perbaikan kinerja perusahaan. Rumusan optimalisasi akan disusun menggunakan analisis SWOT yang merupakan salah satu instrumen analisis yang dipandang cukup ampuh. Keampuhan tersebut terletak pada kemampuan para penentu strategi yang berperan dalam organisasi (Siagian 2004). Menurut Retnowati (2011) analisis situasi SWOT merupakan awal proses perumusan strategi untuk menemukan kesesuaian strategis antara peluang eksternal dan kekuatan internal, di samping memperhatikan ancaman eksternal dan kelemahan internal. Kekuatan dan kelemahan internal adalah segala kegiatan dalam kendali organisasi yang bisa dilakukan dengan sangat baik atau buruk. Kekuatan dan kelemahan tersebut ada dalam kegiatan manajemen, pemasaran, keuangan/ akuntansi, produksi/operasi, penelitian dan pengembangan, serta sistem informasi manajemen di setiap perusahaan. Peluang dan ancaman eksternal juga dapat diidentifikasi merujuk pada peristiwa dan tren ekonomi, sosial, budaya, demografi, lingkungan, politik, hukum, pemerintahan, teknologi, dan persaingan yang dapat menguntungkan atau merugikan suatu organisasi secara berarti di masa depan. Peluang dan ancaman sebagian besar di luar kendali suatu organisasi (David 2004). Hasil identifi-kasi faktor internal dan eksternal dapat digunakan untuk 
merumuskan analisis matriksinternal factor analysis summary (IFAS) dan matriksexternal factor analysis summary (EFAS). Matriks IFAS dan EFAS menunjukkan skor, bobot, dan jumlah nilai total dari masing-masing faktor berdasarkan hasil observasi dan evaluasi kondisi PT Sinar Pandawa seperti tercantum pada tabel 4 berikut ini faktor internal (kekuatan dan kelemahan) dalam pemanfaatan limbah Cair

Tabel 4 Matriks Analisis Secara Faktor Internal

\begin{tabular}{llll}
\hline Kekuatan & Bobot & Skor & Total \\
\hline $\begin{array}{l}\text { Perusahaan menerapkan sistem HACCP } \\
\text { (Hazard Analysis Critical Control Point), di }\end{array}$ & 0,19 & 0,57 \\
dalamnya termasuk upaya pencegahan \\
dampak transportasi.
\end{tabular}

Tabel 5. Matriks Analsis Secara Faktor Eksternal

\begin{tabular}{|c|c|c|c|}
\hline Peluang & Bobot & Skor & Total \\
\hline $\begin{array}{l}\text { Mendapatkan teknologi yang lebih } \\
\text { ramah lingkungan }\end{array}$ & 4 & 0,20 & 0,8 \\
\hline
\end{tabular}


Harahap, S., Z. Lubis, \& Abdul Rahman. Analisis Potensi dan Strategi Pemanfaatan Limbah Kelapa Sawit di Kabupaten Labuhanbatu

\begin{tabular}{|c|c|c|c|}
\hline $\begin{array}{l}\text { Mendapatkan nilai tambah secara } \\
\text { ekonomi (economic benefit). }\end{array}$ & 4 & 0,20 & 0,8 \\
\hline $\begin{array}{l}\text { Abu boiler dapat diaplikasikan langsung } \\
\text { sebagai sumber pupuk kalium, tankos } \\
\text { sebagai pupuk dengan cara menjadikan } \\
\text { mulsa dan pengomposan. Ampas inti } \\
\text { digunakan sebagai pakan ternak. }\end{array}$ & 4 & 0,18 & 0,72 \\
\hline Total Peluang & & & 2,32 \\
\hline Ancaman & Bobot & Skor & Total \\
\hline $\begin{array}{l}\text { Keterbatasan lahan di area PKS Sinar } \\
\text { Pandawa untuk menggunakan sistem } \\
\text { kolam terbuka (limited area). }\end{array}$ & 4 & 0,17 & 0,68 \\
\hline $\begin{array}{l}\text { Perubahan alat proses membawa } \\
\text { dampak pada perubahan kualitas, } \\
\text { kuantitas dan jenis limbah yang } \\
\text { dihasilkan di PT Sinar Pandawa }\end{array}$ & 3 & 0,12 & 0,36 \\
\hline $\begin{array}{l}\text { Terdapat dua sumber pencemaran gas } \\
\text { yang keluar dari PT Sinar Pandawa yaitu } \\
\text { boiler yang menggunakan serat dan } \\
\text { cangkang sebagai bahan bakar dan juga } \\
\text { incinerator yang membakar tankos } \\
\text { untuk mendapatkan abu kalium. }\end{array}$ & 4 & 0,15 & 0,6 \\
\hline $\begin{array}{l}\text { Total Ancaman } \\
\text { Selisih Total Peluang }- \text { Total Tantangan }=0\end{array}$ & $-\mathrm{T}=\mathrm{y}=0,64$ & & 1,64 \\
\hline
\end{tabular}

Berdasarkan matriks IFAS diperoleh sumbu $x=1,41$ dan dari matriks EFAS diperoleh sumbu $y=0,64$ sehingga $(x, y)=(1.41,0.64)$ berada di kuadran I (positif,positif).

Matriks kuadran SWOT PT. Sinar Pendawa dimana posisi tersebut menunjukkan PT. Sinar Pendawa sebagai perusahaan yang kuat dan berpeluang, rekomendasi strategi yang diberikan adalah berpotensi, artinya perusahaan dalam kondisi prima dan mantap sehingga sangat dimungkinkan untuk terus melakukan poetnsi yang besar, memperbesar pertumbuhan dan meraih kemajuan secara maksimal dalam pengolahan limbah cair. Selanjutnya digunakan matriks SWOT berdasarkan hasil klasifikasi terhadap berbagai kemungkinan dari faktor internal dan eksternal untuk mempermudah dalam pengambilan keputusan sebagai berikut :Untuk mengoptimalkan pengelolaan limbah padat, perusahaan dapat melakukan upaya pengurangan limbah padat dan cair dengan menginventarisasi seluruh limbah yang dihasilkan agar dapat dikelola dengan baik. Salah satu upaya yang dapat dioptimalkan adalah melakukan pengomposan dan aplikasi mealui lahan sawit. Matriks SWOT yang telah disusun menghasilkan 4 strategi yang dapat diterapkan sebagai upaya optimalisasi kinerja pengelolaan lingkungan PT.Sinar Pandawa yaitu, sebagai berikut :

1. Strategi SO (Strenghts Opportunities) 
Penyusunan rencana pembangunan metan capture di areal IPAL PKS Sinar Pandawa. Mengembangkan inovasi pemanfaatan limbah padat bekerja sama dengan masyarakat sekitar.

\section{Strategi WO (Weakness Opportunities)}

Melakukan evaluasi dan perbaikan kinerja instalasi pengolahan air limbah(IPAL) agar outlet air limbah yang dihasilkan sesuai ketentuan. Hal ini dilakukan agar kualitas air limbah yang dihasilkan dapat memenuhi kebutuhan pupuk organik secara optimal, seperti meningkatkan konsentrasi BOD air limbah yang nilainya tergolong rendah berdasarkan hasil evaluasi terhadap sertifikat uji laboratorium. Selain itu, perlu dilakukan kembali inventarisasi seluruh air limbah yang dihasilkan PKS Sinar Pandawa dan melakukan pengelolaan yang tepat sesuai ketentuan yang berlaku agar tidak mencemari lingkungan.

Penerapan teknologi pemanfaatan Biogas hasil metan capture sebagai pembangkit listrik bekerja sama dengan pihak ketiga untuk disalurkan kepada masyarakat sekitar. Melibatkan masyarakat sekitar dalam kegiatan pemanfaatan abu kerana boiler untuk campuran pembuatan paving dan batako, pemanfaatan tandan kosong kelapa sawit sebagai media untuk budidaya jamur.

3. Strategi ST (Strenghts Threats)

Memberikan masukan dan pendekatan persuasif dalam penetapan kebijakan pemerintah agar tidak memberatkan perusahaan. Mencari alternatif dan menentukan lembaga pengelola limbah serta laboratorium penguji yang memiliki akreditasi dan reputasi yang baik. Menetapkan strategi dan penyusunan program untuk pemenuhan standarminyak sawit berkelanjutan.

\section{Strategi WT (Weakness Threats)}

Melakukan penyesuaian kegiatan pengelolaan dan pemantauan lingkungan mengikuti kebijakan peraturan lingkungan terbaru. Mengadakan pelatihan untuk meningkatkan kompetensi personil yang menangani kegiatan pengelolaan dan pemantauan lingkungan. Rutin mengadakan pelatihan dan pemahaman prinsip dan kriteria minyak sawit berkelanjutan kepada seluruh karyawan.

Tabel 6. Matrik Analisa SWOT PT. Sinar Pandawa

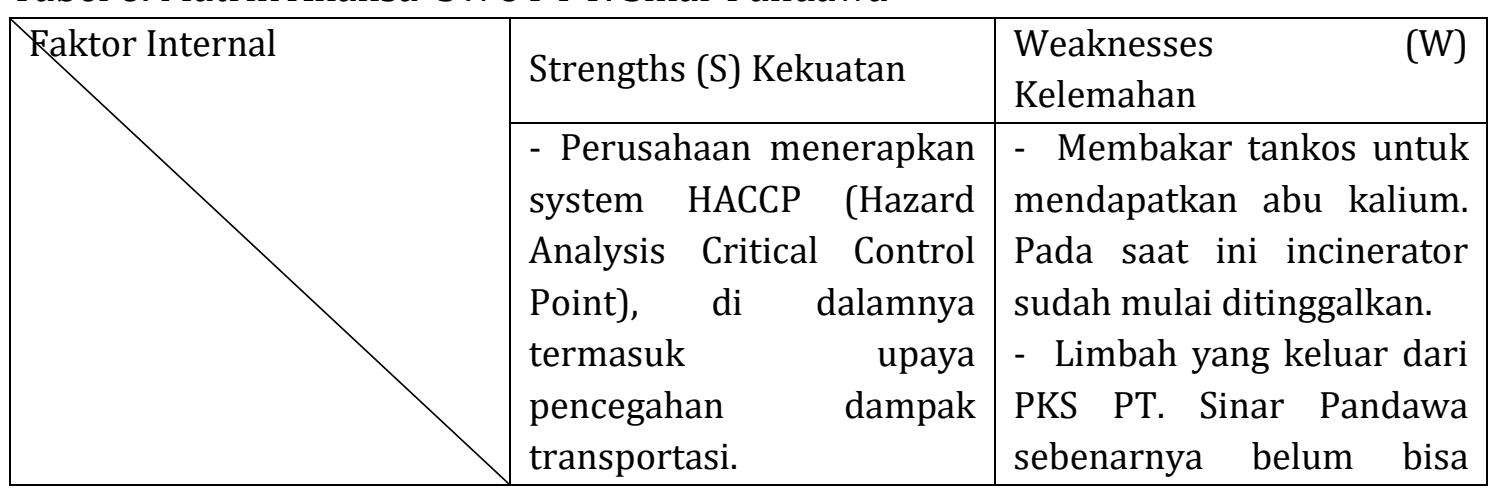


Harahap, S., Z. Lubis, \& Abdul Rahman. Analisis Potensi dan Strategi Pemanfaatan Limbah Kelapa Sawit di Kabupaten Labuhanbatu

\begin{tabular}{|c|c|c|}
\hline Faktor Eksternal & $\begin{array}{lr}\text { - Perusahaan terus } \\
\text { berupaya melakukan } \\
\text { inisiatif untuk menghemat } \\
\text { penggunaan air dan } \\
\text { memiliki ketersediaan } \\
\text { dana yang memadai untuk } \\
\text { kegiatan pengelolaan } \\
\text { limbah pabrik kelapa sawit } \\
\text { - } \\
\text { melaksanakan pengukuran } \\
\text { baku mutu limbah pabrik } \\
\text { kelapa sawit perbulan. } \\
\text { - Komitmen untuk menjadi } \\
\text { perusahaan yang ramah } \\
\text { lingkungan ran } \\
\text { diupayakan ran } \\
\text { menurunkan } & \text { juga } \\
\text { pencemaran. } & \text { beban }\end{array}$ & $\begin{array}{l}\text { dikatakan } 100 \% \text { limbah, } \\
\text { lebih tepat dikatakan } \\
\text { produk pupuk. } \\
\text { - Aplikasi lahan (Land } \\
\text { Application), system ini } \\
\text { tidak disarankan karena } \\
\text { memerlukan lokasi dan } \\
\text { biaya yang besar. } \\
\text { - Limbah menjadi perhatian } \\
\text { PKS PT. Sinar Pandawa } \\
\text { adalah limbah cair. }\end{array}$ \\
\hline $\begin{array}{l}\text { Opportunitties }(0) \\
\text { Peluang }\end{array}$ & $\begin{array}{l}\text { Strategi SO } \\
\text { (Strengths Opportunities) }\end{array}$ & $\begin{array}{l}\text { Strategi WO } \\
\text { Minimalisasi kelemahan } \\
\text { dengan memanfaatkan } \\
\text { peluang }\end{array}$ \\
\hline $\begin{array}{l}\text { - Mendapatkan teknologi } \\
\text { yang lebih ramah } \\
\text { lingkungan. } \\
\text { - Mengurangi pemakaian } \\
\text { pupuk anorganik pada } \\
\text { tanaman kelapa sawit. } \\
\text { - Air limbah dapat } \\
\text { diaplikasikan langsung } \\
\text { sebagai sumber pupuk. } \\
\text { Tankos untuk mulsa. }\end{array}$ & $\begin{array}{l}\text { - Keterbatasan lahan di PT. } \\
\text { Sinar Pandawa } \\
\text { menggunakan kolam } \\
\text { terbuka. } \\
\text { - Perubahan alat proses } \\
\text { membawa dampak pada } \\
\text { perubahan kualitas, } \\
\text { kuantitas dan jenis limbah } \\
\text { yang dihasilkan } \\
\text { - Terdapat } 2 \text { sumber } \\
\text { pencemaran gas yang } \\
\text { keluar dari PKS PT. Sinar } \\
\text { Pandawa yaitu boiler dan } \\
\text { incinerator. }\end{array}$ & $\begin{array}{l}\text { - Melakukan evaluasi dan } \\
\text { perbaikan kinerja instalasi } \\
\text { pengolahan air limbah agar } \\
\text { out limbah sesuai } \\
\text { ketentuan. } \\
\text { - Penerapan teknologi } \\
\text { pemanfaatan limbah cair } \\
\text { sebagai pupuk, pakan } \\
\text { ternak dengan pihak ketiga } \\
\text { untuk disalurkan ke } \\
\text { masyarakat } \\
\text { - Melibatkan masyarakat } \\
\text { sekitar dalam pemanfaatan } \\
\text { limbah. } \\
\text { [ }\end{array}$ \\
\hline $\begin{array}{l}\text { Threats (T) } \\
\text { Ancaman }\end{array}$ & $\begin{array}{l}\text { Strategi ST } \\
\text { (Strengths Threats) }\end{array}$ & $\begin{array}{l}\text { Strategi WT } \\
\text { Minimalisasi kelemahan } \\
\text { dengan menyikapi ancaman }\end{array}$ \\
\hline
\end{tabular}




\begin{tabular}{|c|c|c|}
\hline $\begin{array}{l}\text { - Perubahan kebijakan dan } \\
\text { peraturan terkait } \\
\text { pengelolaan lingkungan. } \\
\text { - Terbatasnya jumlah } \\
\text { lembaga pengelola limbah } \\
\text { dan laboratorium penguji } \\
\text { yang memenuhi ketentuan } \\
\text { yang berlaku disekitar PKS } \\
\text { PT. Sinar Pandawa. }\end{array}$ & $\begin{array}{l}\text { - Memberikan masukan } \\
\text { dan pendekatan persuasif } \\
\text { dalam penetapan kebijakan } \\
\text { pemerintah agar tidak } \\
\text { memberatkan perusahaan. } \\
\text { - Mencari alternative dan } \\
\text { menentukan lembaga } \\
\text { pengelola limbah serta } \\
\text { laboratorium penguji yang } \\
\text { memiliki akreditasi dari } \\
\text { lembaga yang berwenang. }\end{array}$ & $\begin{array}{l}\text { - Melakukan penyesuaian } \\
\text { kegiatan pengelolaan dan } \\
\text { pemantauan limbah padat } \\
\text { dan cair sesuai ketentuan } \\
\text { yang berlaku. } \\
\text { - Mengadakan pelatihan } \\
\text { untuk meningkatkan } \\
\text { kompetensi sumber daya } \\
\text { manusia karyawan yang } \\
\text { menangani pengelolaan } \\
\text { limbah pabrik kelapa sawit } \\
\text { PT. Sinar Pandawa. }\end{array}$ \\
\hline
\end{tabular}


Berdasarkan beberapa strategi yang telah disusun, prioritas strategi yang digunakan adalah strategi SO (strengths opportunities). Penentuan strategi ini berdasarkan pada posisi perusahaan di kuadran 1 hasil dari matriks kuadran

SWOT PKS PT. Sinar Pandawa. Optimalisasi kinerja pengelolaan limbah padat dapat dilakukan dengan upaya minimalisasi melalui inventarisasi seluruh limbah padat yang dihasilkan PKS Sinar Pandawa agar dapat dikelola dengan baik. Salah satu programnya adalah mengurangi timbulan limbah B3 berupa oli bekas dan filter bekas dari operasional genset. Hal ini dapat dilakukan dengan memanfaatkan cangkang dan fiber sebagai bahan bakar boiler untuk menjalankan turbin non processing sehingga mampu menggantikan operasional genset.

\section{SIMPULAN}

PT. Sinar Pandawa memiliki potensi pemanfaatan limbah cair sebesar $50 \%-60 \%$ dari hasil pengolahan tandan buah segar. Janjangan kosong seluruhnya dimanfaatkan sebagai pupuk organik di perkebunan PT. Sinar Pendawa dengan luas areal aplikasi 1.791.04 Ha. Adanya pemanfaatan limbah cair dapat mengurangi penggunaan pupuk anorganik di perkebunan PT. Sinar Pendawa dan penghematan biaya pupuk. Matriks kuadran SWOT PT. Sinar Pendawa dimana posisi tersebut menunjukkan PT Sinar Pendawa sebagai perusahaan yang kuat dan berpeluang, rekomendasi strategi yang diberikan adalah berpotensi.

PT. Pangkatan Indonesia Kabupaten Labuhanbatu telah melaksanakan pengomposan(komposting) sebagai pupuk tanaman perkebunan kelapa sawit terhadap sebagian lahan dari sekitar 2.586,00 Ha. Jenis Limbah cair meliputi: lumpur sekunder, dan bahan yang terkontaminasi minyak sawit. Limbah cair hanya diperkenankan untuk pengomposan di lahan kebun kelapa sawit dan akan mengurangi penggunaan pupuk anorganik, dengan beberapa indikator yang telah dipenuhi oleh PKS PT. Pangkatan Indonesia, yaitu: tersedia instruksi kerja/SOP mengenai pengelolaan limbah cair yang dimanfaatkan sesuai peraturan perundang undangan yang berlaku di bidang lingkungan hidup, rekaman penanganan limbah cair terdokumentasi, tersedia surat izin penyimpanan dan/atau pemanfaatan limbah cair dari instansi terkait. Matriks kuadran SWOT PT. Pangkatan Indonesia dimana posisi tersebut menunjukkan PT. Pangkatan Indonesia sebagai perusahaan yang kuat dan berpeluang, rekomendasi strategi yang diberikan adalah berpotensi.

Strategi optimalisasi kinerja tersebut meliputi: untuk meningkatkan nilai BOD limbah cair dan padat yang bertujuan untuk melakukan pengomposan dan aplikasi lahan sangat berpotensi dilakukan di Kabupaten Labuhanbatu. Pengomposan ini sangat berpeluang dalam usaha pembuatan pupuk organik sehingga akan membutuhkan tenaga kerja. Prioritas strategi dalam pemanfaatan limbah pabrik kelapa sawit adalah aplikasi lahan kebun untuk perusahaan perkebunan kelapa sawit karena tanaman kelapa sawit membutuhkan air sangat banyak untuk pertumbuhan tanaman, namun dari segi lingkungan pengomposan merupakan strategi lebih aman terhadap pencemaran lingkungan. 
Dibutuhkan rekomendasi dalam penetapan kebijakan pemerintah dan melakukan evaluasi terhadap perusahaan pabrik kelapa sawit di Kabupaten Labuhanbatu dalam pengelolaan limbah cair dan padat untuk meminimalkan pencemaran lingkungan dengan metode pemanfaatan aplikasi lahan dan pengomposan. Pengelolaan limbah padat dan cair di PT. Sinar Pandawa dan PT. Pangkatan Indonesia, perlu dilakukan kerjasama dengan pihak ketiga sebagai upaya penyerapan tenaga kerja dan membantu masyarakat sekitar perusahaan terutama petani yang membutuhkan pupuk organik dari limbah.

\section{DAFTAR PUSTAKA}

Elly, Kurniati. (2008). Pemanfaatan Cangkang Kelapa Sawit Sebagai Arang Aktif. Teknik Kimia FTI UP, Jawa Timur.

David, L. (2002). Manajemen Strategi. BPFE, Yokyakarta.

Devendra, C. (1990). Utilization of Feedings Tuff From The Oil Palm . Feedings Tuff for Livestock In South Asia. Serdang, Malaysia.

Dinas Perkebunan Provinsi Sumut. (2015). Rekapitulasi Luas Areal dan Produksi Tanaman Perkebunan. Provinsi Sumatera Utara.

Dinas Kehutanan dan Perkebunan Kabupaten Labuhanbatu. (2015). Tentang Luas Areal Perkebunan Kelapa Sawit. Rantauprapat. Sumatera Utara

Ditjen PPHP. (2006). Pedoman Pengelolaan Limbah Industri Kelapa Sawit. Departemen Pertanian. Jakarta.

Hasan, O.A. and M. Ishida. (1991). Status of utilization of selected fibrous crop residues and animal performance with special emphasis on processing of oil palm frond (OPF) for ruminant feed in Malaysia. Malaysia

Husein, Umar. (2003). Metode Riset Bisnis. Jakarta: PT Gramedia Pustaka Utama

Hutagalung and Jalaludin. (2002). Feeds for Farm Animal from the Oil Palm. Serdang, Malaysia.

Glueck William F \& Jauch Lawrence R. (2004). Manajemen Dan Strategis Kebijakan Perusahaan. Erlangga, Jakarta.

Kardila. (2011). Karakteristik Air Limbah Industri Minyak Kelapa Sawit. Institut Teknologi Sepuluh Nopember, Surabaya.

Ketaren, S. (1986). Pengantar Teknologi Minyak dan Lemak Pangan. Cetakan Pertama. UI -Press, Jakarta.

Mubyarto. (2001). Pengantar Ekonomi Pertanian. LP3ES. Jakarta.

Mustafa, Nur dan Hadi. (1998). Teknik Berkebun Kelapa Sawit. Edisi Pertama Cetakan Pertama. Adi Karya Nusa, Jakarta

Pearce, J., \& Robinson, R. (1998). Strategic Management: formulation, Implementation, and Control, 7th Edition. McGraw-Hill, Malaysia.

Porter, M.E. (2003). Cooperative Advantage ; Creating and Sustain Superior Performance. Free Press, New York.

Rangkuti, F. (2006). Analisis SWOT Teknik Membedah Kasus Bisnis. Gramedia Pustaka Utama, Jakarta.

Risza, R. (2005). Budidaya Kelapa Sawit. AAK. Kanisery. Yogyakarta.

Rustiadi, E., Barus, B., Prastowo, \& Iman L.S. (2005). Kajian Daya Dukung Lingkungan Hidup .Crestpent Press, Jakarta.

Siregar, Z., Hasnudi, S. Umar, I. Sembiring. (2005). Tim Jurusan Peternakan Fakultas Pertanian USU. Bekerjasama dengan PTPN IV dalam Rangka Membangun Pabrik Pakan Ternak Berbasis Limbah Sawit.

Soekartawi. (2002). Prinsip Dasar Ekonomi Pertanian: Teori dan Aplikasi, Rajagrafindo Persada, Jakarta

Soetrisno, L. (2008). Pertanian Pada Abad Ke-21. Departemen Pendidikan dan Kebudayaan, Jakarta

Syamsulbahri. (2006). Bercocok Tanam Tanaman Perkebunan Tahunan. GadjaMadaPress, Yogyakarta.

Umar, Husein, (2003). Riset dan Penelitian . Gramedia Pustaka Utama, Jakarta.

Utomo. B.N. \& E.Widjaja. (2004). Limbah Padat Pengolahan Minyak Sawit Sebagai Sumber Nutrisi Ternak Ruminansia. J. Litbang. Pertanian23(1):22-28.

Zahari, M., O. Abu Hassan, H.K. Wong \& J.B. Liang. (2003). Utilization of Oil Palm Frond-based diets for Beef Cattle Production in Malaysia. Asian- Agust, J. Anim Sci.

Zulbardi, M., M. Sitorus, Maryono, \& L.Affandy. (1995). Potensi dan pemanfaatan pakan ternak di daerah sulit pakan. Edisi Khusus Kumpulan Hasil-hasil Penelitian Tahun Anggaran. 1994/1995. Ternak Ruminansia Besar. Balai Penelitian Ternak, Bog 